\title{
Intake assessment of problematic use of medications in a chronic noncancer pain clinic
}

\author{
Leah R Pink RN MN, Andrew J Smith MDCM, Philip WH Peng MBBS FRCPC, Marilyn J Galonski RN BSc, \\ Paul S Tumber MD FRCPC, David Evans MD FRCPC, Doug L Gourlay MD FRCPC FASAM, Lesley Gordon BA, \\ Geoff A Bellingham MD FRCPC, Satnam S Nijjar MD FRCPC, Larry M Picard MD FRCPC, Allan S Gordon MD FRCPC
}

LR Pink, AJ Smith, PWH Peng, et al. Intake assessment of problematic use of medications in a chronic noncancer pain clinic. Pain Res Manage 2012;17(4):276-280.

BACKGROUND: The present article outlines the process of instituting an assessment of risk of problematic use of medications with new patients in an ambulatory chronic noncancer pain (CNCP) clinic. It is hoped that the authors' experience through this iterative process will fill the gap in the literature by setting an example of an application of the 'universal precautions' approach to chronic pain management.

OBJECTIVES: To assess the feasibility and utility of the addition of a new risk assessment process and to provide a snapshot of the risk of problematic use of medications in new patients presenting to a tertiary ambulatory clinic treating CNCP.

METHODS: Charts for the first three months following the institution of an intake assessment for risk of problematic medication use were reviewed. Health care providers at the Wasser Pain Management Centre (Toronto, Ontario) were interviewed to discuss the preliminary findings and provide feedback about barriers to completing the intake assessments, as well as to identify the items that were clinically relevant and useful to their practice. RESULTS: Data were analyzed and examined for completeness. While some measures were considered to be particularly helpful, other items were regarded as repetitive, problematic or time consuming. Feedback was then incorporated into revisions of the risk assessment tool.

DISCUSSION: Overall, it is feasible and useful to assess risk for problematic use of medications in new patients presenting to CNCP clinics.

CONCLUSION: To facilitate the practice of assessment, the risk assessment tool at intake must be concise, clinically relevant and feasible given practitioner time constraints.

Key Words: Chronic pain; Chronic pain clinic; Problematic use; Risk assessment; Universal precautions

\section{L'évaluation, dès l'admission, de l'utilisation problématique de médicaments dans une clinique de gestion de la douleur chronique d'origine non cancéreuse}

HISTORIQUE : Le présent article expose le processus de mise en œuvre d'une évaluation du risque que de nouveaux patients d'une clinique ambulatoire de gestion de la douleur chronique d'origine non cancéreuse (DCONC) utilisent des médicaments de manière problématique. On espère que, par ce processus itératif, cette expérience contribuera à corriger une lacune dans les publications en donnant l'exemple de la mise en application d'une démarche de "précautions universelles » pour la prise en charge de la douleur chronique.

OBJECTIFS : Évaluer la faisabilité et l'utilité d'ajouter un nouveau processus d'évaluation du risque et fournir un cliché du risque que de nouveaux patients qui consultent à une clinique ambulatoire de soins tertiaires pour soigner des DCONC utilisent les médicaments de manière problématique. MÉTHODOLOGIE : Les chercheurs ont analysé les dossiers des patients dans les trois premiers mois suivant la mise en œuvre de l'évaluation, dès l'admission, du risque d'utilisation problématique de médicaments. En entrevue avec les dispensateurs de soins du Wasser Pain Management Centre de Toronto, en Ontario, ils ont discuté des résultats préliminaires et obtenu des commentaires sur les obstacles à vaincre pour effectuer les évaluations initiales, ainsi que pour déterminer les points qui étaient pertinents et utiles à leur pratique sur le plan clinique.

RÉSULTATS : Les chercheurs ont analysé les données et en ont examiné l'exhaustivité. Certaines mesures étaient considérées comme particulièrement utiles, tandis que d'autres étaient perçues comme répétitives, problématiques ou chronophages. Les chercheurs ont incorporé les commentaires aux révisions de l'outil d'évaluation du risque.

EXPOSÉ : Dans l'ensemble, il est faisable et utile d'évaluer le risque d'utilisation problématique des médicaments chez les nouveaux patients qui consultent dans des cliniques de gestion de la DCONC.

CONCLUSION : Pour faciliter l'évaluation, l'outil d'évaluation du risque à l'admission doit être concis, pertinent sur le plan clinique et faisable compte tenu des contraintes de temps des praticiens.

$A$ ssessing the risk of problematic use of medications is importAant in chronic pain management because treatment so often includes complex pharmacotherapy. The Wasser Pain Management Centre (WPMC) at Mount Sinai Hospital (Toronto, Ontario) is an ambulatory clinic situated in an urban teaching hospital, specializing in chronic noncancer pain (CNCP). The clinic sees approximately 7000 patients per year and incorporates the expertise of a variety of health disciplines including neurology, anesthesiology, gynecology, dentistry, psychiatry, nursing, sex therapy and cognitive behavioural therapy, as well as other closely linked external services to which we frequently refer (eg, physiotherapy, acupuncture and chiropractics).

Until recently, each practitioner at the WPMC assessed the risk of problematic medication use in their own way. One of the physicians at the WPMC, along with other colleagues, has performed a great deal of work in the area of pain and addiction, and has written extensively on risk assessment. One of the main features of his work has been termed 'universal precautions', after the infectious disease approach. Because there is no definitive method of identifying chronic pain patients who will develop a problematic use of medications, Gourlay et al (1) proposed the concept of universal precautions, which offers health care providers (HCPs) a uniform approach to assessment. Universal precautions in chronic pain is the application of precautions to all patients being considered for, or treated with, opioid medications (1). While opioid medications can lead to difficulties for some patients, in our experience, problematic use is not limited to this class of medications. The clinical team at WPMC decided to attempt to implement a uniform Problematic Use Intake Assessment (PUIA) to be used with all new patients.

To begin the process, a literature search was conducted to determine whether other CNCP clinics were establishing similar initiatives in the

Wasser Pain Management Centre, Mount Sinai Hospital, Toronto, Ontario

Correspondence: Ms Leah Pink, Wasser Pain Management Centre, Joseph and Wolf Lebovic Health Complex, Mount Sinai Hospital,

600 University Avenue, Toronto, Ontario M5G 1X5. Telephone 416-586-4800 ext 2979, fax 416-586-5067,

e-mail lpink@mtsinai.on.ca 
area of chronic pain and the assessment of risk of problematic medication use. The search was conducted using the following databases: Ovid MEDLINE, limited to 1996 to 2008, with subject headings: "pain clinics" and "substance-related disorders"; Ovid CINAHL, limited to 1982 to 2008, with the subjects headings: "pain clinics" and "substance abuse"; PubMed, using keywords: "substance abuse in pain clinics", "problematic use in chronic pain" and "problematic use of opioids in chronic pain", as well as MeSH subject headings: "pain clinics", "substance related disorders", "substance abuse detection" or "substance abuse treatment centres".

Articles were narrowed to five relevant studies that examined problematic substance use specifically in CNCP clinics (2-6). While some studies concluded that prescribing opioids for chronic pain management resulted in few problems (2,3), others investigated specific ways to assess addiction (4-6). While there is much discussion of prescription practices and risk assessment with opioids, there is little in the literature that examines the process of instituting this type of approach.

\section{Aim}

The aim of the present study was to report on the process of a change in practice, working toward adopting a uniform assessment of problematic use of medications in the chronic pain population. The present article discusses the feasibility and utility of this change in practice while, at the same time, providing a snapshot of the risk factors in new patients referred to an ambulatory $\mathrm{CNCP}$ clinic in a tertiary teaching hospital. Our experience in instituting a PUIA fills a gap in the literature and sets an example of an application of the universal precautions approach to the assessment of problematic substance use.

\section{METHODS}

The PUIA was developed through an iterative process in a series of meetings with the WPMC clinical team. Initial meetings of the group, which incorporated an interprofessional group of HCPs at the clinic, identified several measures to include in the assessment. These discussions produced a two-page assessment of new patients to be administered by an HCP that combined several established measures (CAGE-AID [Have you ever felt you should cut down on your drinking?; Have people annoyed you by criticising your drinking?; Have you ever felt bad or guilty about your drinking?; Have you ever had a drink first thing in the morning to steady your nerves or get rid of a hangover (eye-opener)?; Adapted to Include Drugs], the Opioid Risk Tool [ORT]; and the Potential Aberrant Drug-Related Behaviour), as well as items that the pain and chemical dependency specialist at the WPMC uses to assess patients identified as high risk for problematic use.

The first draft of the risk assessment included several tools: the CAGE-AID, a tool that measures the use of both drugs and alcohol together (7); the ORT, designed to predict risk of aberrant behaviours in patients treated with opioids (specifically examining family and personal history of substance abuse, age, history of preadolescent sexual abuse, and psychological disease) (8); the Potential Aberrant Drug-Related Behaviour, a segment of a tool used to identify behaviours that point to the problematic use of medications (9); a section used to identify recreational or street drug use that was adopted from the clinic intake package; the Pain and Chemical Dependency Worksheet, a section of questions adapted from another assessment form used in the clinic for chronic pain patients with concurrent abuse and/or dependency issues; a medication list; a segment on signs of abuse/dependency; and a section for urine drug testing.

The PUIA was introduced to all clinic HCPs at a meeting and then again by e-mail. The PUIA is administered one time at the initial intake visit with a new patient by a HCP, including nurses, physicians, residents and fellows, in an interview style format, which takes approximately $5 \mathrm{~min}$ to complete. This was added to the standard initial assessment of new patients along with health history, physical assessment, diagnosis and treatment plan.

\section{TABLE 1}

\section{CAGE-AID score}

\begin{tabular}{lc}
\hline Score (out of 4) & $\mathbf{n}(\%)$ \\
\hline 0 & $31(59.6)$ \\
1 & $7(13.5)$ \\
2 & $6(11.5)$ \\
3 & $5(9.6)$ \\
4 & $2(3.8)$ \\
Missing & $1(1.9)$ \\
Total & $52(100.0)$ \\
\hline
\end{tabular}

CAGE-AID Have you ever felt you should Cut down on your drinking?; Have people Annoyed you by criticising your drinking?; Have you ever felt bad or Guilty about your drinking?; Have you ever had a drink first thing in the morning to steady your nerves or get rid of a hangover (Eye-opener)?, Adapted to Include Drugs

Following approval by the Mount Sinai Hospital Research Ethics Board, a chart review was conducted with all new patients seen in the summer of 2008 (July to October), the first three months of the change in practice. New patients were identified in the clinic schedule. Data were extracted, entered into SPSS (IBM Corporation, USA), analyzed using descriptive statistics and examined for completeness.

Once the analysis was complete, the lead author met with HCPs to discuss the preliminary findings and obtain their feedback regarding feasibility, utility and barriers to completing the assessment (including representation from anesthesiology, neurology and nursing). Following completion of the feedback meetings, revisions incorporating the information provided by HCPs and based on the analysis were used to revise the PUIA (Appendix A).

\section{RESULTS}

A total of 52 charts were reviewed. Data were entered and analyzed in SPSS using descriptive statistics. An analysis of missing variables was also conducted. Based on the preliminary results and feedback from HCPs, it was clear that while some items in the PUIA were considered to be useful, other items were viewed to lack utility and were deemed repetitive or time consuming.

The CAGE-AID was well-answered across the board (response rate $98.1 \%$ ). HCP feedback indicated that the tool was familiar and generally found to be time efficient and easy to interpret. Sixty per cent of patients scored 0 on the four-point scale ( 0 being the lowest risk and 4 being the highest) and only $3.8 \%$ of patients scored $4 / 4$ (Table 1).

The ORT was also answered well overall (with only $7.7 \%$ missing responses). Some of the feedback from HCPs was that, while the ORT was not commonly used in the clinic before the present initiative, similar to the CAGE-AID, it was easy to implement and interpret, and provided useful information. Scoring the ORT was also reported to be straight forward.

One of the barriers encountered in administering the ORT was the question regarding the history of preadolescent sexual abuse. Feedback indicated that the question had the potential to lead to unpleasant reactions in some patients, which can be an added challenge to manage when there is already a limited period of time to assess, diagnose and treat a patient with chronic pain. While the relevance of the topic was never questioned by HCPs, this item, along with a later section that asks about physical, emotional and sexual abuse history, posed additional challenges to the HCP and, in at least a few cases, contributed to nonresponse. Despite the issues raised, HCPs were in agreement that this was an important component of assessing risk.

In the analysis of the ORT, individuals who did and did not report a family history of alcohol abuse were evenly divided ( $46.2 \%$ each). Family history of illegal and prescription drug abuse was much less frequent $(11.5 \%)$, while personal history of substance use ranged from $11.5 \%$ for prescription drugs to $23.1 \%$ for alcohol (Table 2 ). 
TABLE 2

Personal history of substance abuse

\begin{tabular}{lccc}
\hline & Alcohol abuse & Illegal drug abuse & $\begin{array}{c}\text { Prescription drug } \\
\text { abuse }\end{array}$ \\
\hline No & $36(69.2)$ & $38(73.1)$ & $42(80.8)$ \\
Yes & $12(23.1)$ & $10(19.2)$ & $6(11.5)$ \\
Missing & $4(7.7)$ & $4(7.7)$ & $4(7.7)$ \\
Total & $52(100.0)$ & $52(100.0)$ & $52(100.0)$ \\
\hline
\end{tabular}

Data presented as $n$ (\%)

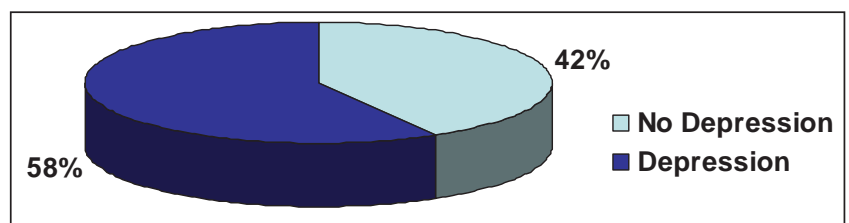

Figure 1) Diagnosis of depression at intake

A diagnosis of depression, which was based on patient self-report, was indicated in $55.8 \%$ of patients screened, slightly higher than the mean of $52 \%$ found in similar pain clinic populations in a review of the literature (10) (Figure 1).

Overall, ORT scores demonstrated that $53.8 \%$ of patients at intake assessment were in the low risk category, while $15.4 \%$ were moderate risk and $25 \%$ were high risk (Table 3 ). The ORT was answered well and only slightly less frequently than the CAGE-AID.

The vast majority of the items in the Aberrant Drug-Related Behaviour tool were not answered (range $71.2 \%$ to $98.1 \%$ ). There is no way to know definitively whether this level of nonresponse was because the section was overlooked or simply not applicable; however, feedback from the team questioned the utility of this tool for several reasons. First, there was no scoring method for the item because it is only a segment of a larger instrument. As well, it was reported that the questions were not well-suited for a new patient assessment and would make more sense as an on-going tool to assess aberrant behaviours once there is an established history of prescribing to the patient. Items in this section refer to patterns of behaviours and characteristics of a patient that a physician would only come to know after at least a couple of visits (ie, frequent early renewals, obtaining prescriptions from more than one doctor). In addition, many of the items are not suited to an interview-style assessment. Finally, there was also a sense that some questions were too general to be considered relevant predictors of problematic use (ie, involvement in a motor vehicle accident).

Of interest, the two most commonly selected aberrant behaviours were the use of pain medications in response to situational stressors and involvement in a motor vehicle or other accident $(5.8 \%$ and $11.5 \%$, respectively). It is unclear what significance, if any, these items hold with regard to risk for problematic use. It is possible that the 'accident' item is disproportionately high because it is a common cause of injury, which may lead to chronic pain.

Patients were asked about their recreational or street drug use as a component of the intake assessment. Missing items ranged from 3.8\% to $100 \%$. Similar to the previous section, there is no way to know whether the question was simply overlooked or deemed not applicable.

When asked about their experiences with these questions, HCPs reported that they found that patient's answers were often reluctant or vague, which may have contributed to the high number of nonresponses. As a teaching hospital, there were also a variety of medical trainees from different backgrounds administering the PUIA who may not have been familiar with asking these types of questions. Finally, some reported skipping all or part of this section when the CAGEAID and ORT showed low risk and/or no history of substance abuse because it was then deemed irrelevant.
TABLE 3

Opioid Risk Tool score results

\begin{tabular}{lc}
\hline Risk & $\mathbf{n}(\%)$ \\
\hline Low & $28(53.8)$ \\
Moderate & $8(15.4)$ \\
High & $13(25.0)$ \\
Missing & $3(5.8)$ \\
Total & $52(100.0)$ \\
\hline
\end{tabular}

Low risk score 0 to 3 ; moderate risk score 4 to 7 ; high risk score $\geq 8$

Overall, 59.6\% reported having never used recreational or street drugs. Only $7.7 \%$ admitted to current use, while $26.9 \%$ said they had used in the past. None of the patients assessed reported any experience with the use of amphetamines or heroin. While most patients had never used cocaine or crack (78.8\%), 15.4\% had in the past, and none were currently using.

The most commonly used substances were in the category of marijuana, cannabis and hashish. While $59.6 \%$ of patients reported to have never smoked marijuana or hashish, $30.8 \%$ reported past use and $5.8 \%$ indicated current use.

For all of the above drug categories, there was space provided for HCPs to enter when the patients had last used the drug and the route of drug use, but these sections were so poorly answered that there is very little to report, ranging anywhere from $40 \%$ to $100 \%$ missing. HCPs were asked about this and they cited time factors and patient reluctance to answer these questions. Some skipped the route of drug use when it was considered to be particularly obvious; for example, cocaine taken nasally and crack being smoked. The problem with this is that there are a variety of routes of administration that may not be considered obvious to all; for example, cocaine can also be injected. Because time is such a limiting factor in new patient assessments, decisions to leave out items deemed less relevant or obvious were often made, which posed a challenge to this process.

Most patients had never received treatment for substance abuse, although $13.5 \%$ said that they had, while $7.7 \%$ of the time, this question was left unanswered. Of those who reported receiving substance abuse treatment, $71.4 \%$ received residential treatment, $28.6 \%$ were with Alcoholics Anonymous and $42.9 \%$ were with Narcotics Anonymous.

There were several challenges in terms of response rates with the group of questions derived from the Pain and Chemical Dependency Worksheet. Missing variables in this section ranged from $23.1 \%$ to $98.1 \%$. Some HCPs were not clear on the significance of some of the questions being asked or, more specifically, how responses should be interpreted or translated into a meaningful objective measure of risk.

While the HCP who created the worksheet developed the questions from evidence and experience, there was no systematic method for the rest of the team to score the items. So while they likely have a significant utility in this setting, the team needs to gain a better understanding of the evidence behind the worksheet questions. It was suggested that an educational in-service be held for HCPs in the clinic so there could be a common understanding of its use and interpretation.

Another factor that likely played a role in the poor response rates in this section is related to relevance. Questions were considered to be more relevant and answered more thoroughly when patients were exhibiting or identified as having 'red flags', as one HCP stated. This means patients who are at high risk of problematic use of medications. The physician who developed the original worksheet from which the PUIA was adapted has a practice seeing patients who have been identified as being at high risk and referred for that reason. If a patient scored high on the CAGE-AID and/or ORT, HCPs were more likely to complete the PUIA more thoroughly.

Finally, HCPs found that patients were unable to recall some of the specifics such as age of 'first drink' and age of 'first drunk'; therefore, the reliability of patient recall was questioned. 
When it came to addressing past suicidality, $90 \%$ to $98.1 \%$ of the time, these questions were not answered. Given the high rate of depression identified in the ORT, this was a surprising figure. When asked about this, HCPs indicated that they always ask about suicide if they have any indication it might be a problem. HCPs also stated that the formatting of that section was particularly problematic because there was too much in a small section. It was suggested that this section be revised and reformatted to facilitate a better response rate.

There was sexual, physical and emotional trauma reported by $19.2 \%, 28.8 \%$ and $19.2 \%$ of subjects, respectively, although almost $54 \%$ of these questions were not answered. In the ORT, $14.7 \%$ reported a history of sexual abuse and only $7.7 \%$ of the questionnaires did not provide this information. It is possible that time was taken to answer this section of the intake assessment more diligently when there were red flags present, which may explain the sexual trauma number discrepancy. There was also a concern with the sensitivity of the question in the context of time limitation. It is possible that asking about past abuse without the time to address patient reactions to the questions may have had an influence on the response rates.

Patients reported taking a number of medications, which were grouped into categories for the purpose of data analysis. The most common of the groups were the opioid analgesics (27.9\%) (Figure 2).

As previously mentioned, time was a major barrier to completing the intake assessment. The medication list was viewed to be repetitive because the information was listed in the chart and in the HCP consultation note. In later versions of the PUIA this section was removed.

One of the major complaints about the section on signs of abuse/ dependency centred not on the relevance of the items, because it is clear they are crucial to assessing risk of problematic use, but on the lack of time. Based on feedback, this section was later omitted, both in the interest of time and because the assessment was for screening based on history rather than physical assessment.

Drug screening urine samples were reportedly submitted in 19.2\% of patients, but many practitioners skipped this question. Similar to the Chemical Dependency Worksheet, HCPs were more apt to send a sample when there were red flags, such as high scores on the ORT and CAGE-AID. Some HCPs see patients on a more ongoing basis than others. For example, HCPs who see patients mostly to assess their suitability for anesthetic blocks are less inclined to send a urine drug screening specimen than the physician who is likely to be involved in prescribing medications and overseeing the patient's use of opioids. Other barriers to this question were the lack of time and the priority placed on physical assessment.

\section{DISCUSSION}

The results of the present study offer some important information and have informed subsequent iterations of the PUIA. It is hoped that our experience will provide guidance to other centres that treat $\mathrm{CNCP}$ and who are aiming to standardize their approach to risk assessment of problematic use of medication.

A number of barriers to administering the PUIA were identified by HCPs based on the results of the chart review. Time constraint was probably the most significant barrier to the PUIA identified. Decisions to leave out items that individual HCPs deemed less relevant were often made, which may have reflected their own professional biases and were also guided by whether the CAGE-AID and ORT demonstrated any red flags.

As a teaching hospital, a variety of HCPs, as well as students, residents and clinical fellows, continuously come through the clinic. These are often the HCPs conducting PUIAs with new patients presenting to the clinic and so there may have been some variability in how the assessments were performed.

Overall, this process identified several items that need to be considered when adopting a PUIA. First, this is a knowledge translation opportunity in that we need to gain a better understanding of how to administer and interpret the information we are collecting and to clearly

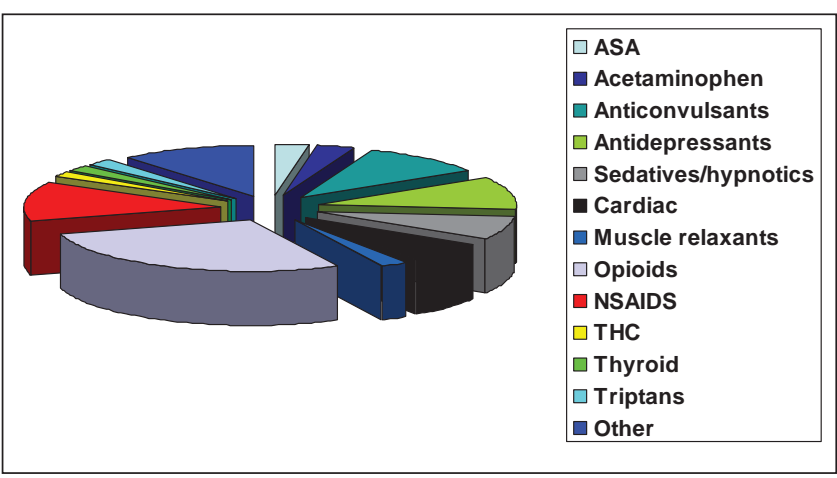

Figure 2) Medication use at intake. ASA Acetylsalicylic acid; NSAIDs Nonsteroidal anti-inflammatory drugs; THC Tetrahydrocannabinol

communicate that to the large number of trainees that come through the WPMC. As well, another item that was added to the revised intake assessment based on both the literature and feedback received was an overall clinical assessment of risk at the end of the intake assessment (11). This will enable the HCPs to collate and process the information they have collected and, based on their clinical judgment, make a decision on whether the patient is low, moderate or high risk. Stratification will be particularly useful in guiding future care and will facilitate professional communication by providing vital information to other collaborating and consulting members of the team.

Finally, it was speculated that patients involved in medicolegal issues may be particularly reluctant to respond accurately about medication and drug use for fear of potential legal ramifications. A question was subsequently added to the PUIA to identify patients involved in that type of consultation so it could be incorporated into the overall assessment of risk.

\section{CONCLUSIONS}

There is little information in the literature regarding the experience of chronic pain management clinics instituting an approach to assessing risk of problematic use. The trend to move beyond the collective fear of prescribing opioids has resulted in a degree of complacency and a lack of safeguards in place to identify and manage high-risk patients (12). A universal approach to risk assessment will raise the standard of care in treating patients suffering from chronic pain (1).

The present chart review provides a snapshot of the risk of problematic use in new patients presenting to a CNCP centre and fills gaps in the literature by providing an example to other pain clinics of the application of 'universal precautions'; an approach to the assessment of problematic use in chronic pain.

A number of important factors need to be examined uniformly in new patients presenting to $\mathrm{CNCP}$ clinics to assess risk for problematic use of medications. However, to facilitate the practice, the intake assessment must be concise, clinically relevant and feasible given practitioner time constraints. HCP feedback based on the analysis of the chart review gave us some valuable information about what worked and what needed to be adapted, giving us some clear guidance for subsequent revisions.

As we learn more about the risk of problematic medication use, and based on the experience we are sure to accumulate applying universal precautions in our everyday practise, our approach to assessment needs to be re-evaluated and possibly revised. Future research is needed in this developing area of CNCP management.

DISCLOSURES: This study was funded by The Mount Sinai Hospital/ Purdue Pharma Research Partnership in Pain and Addiction and was previously presented as a poster at the CPS conference in Quebec City in 2009. 


\section{APPENDIX A: REVISED PUIA}

\begin{tabular}{|c|c|c|c|c|}
\hline \multicolumn{5}{|c|}{ 2. Opioid Risk Tool (Webster \& Webster, 2005) } \\
\hline \multicolumn{5}{|c|}{$\begin{array}{l}\text { 3. Which of the following recreational or street drugs has the patient used? } \\
\square \text { none or: }\end{array}$} \\
\hline & Past & Present & Route & Last Used \\
\hline Amphetamines & $\square$ & $\square$ & & \\
\hline \multicolumn{5}{|l|}{ Cocaine or crack } \\
\hline \multicolumn{5}{|l|}{ Heroin } \\
\hline \multicolumn{5}{|l|}{ Marijuana, Cannabis, Hashish } \\
\hline \multicolumn{5}{|l|}{ LSD, Mescaline, PCP, Ecstacy } \\
\hline \multicolumn{5}{|c|}{ 4. Has the patient ever received treatment for substance abuse? $\square$ No $\square$ Yes } \\
\hline \multicolumn{5}{|c|}{$\begin{array}{l}\text { (a) If yes, was it residential? } \square \text { No } \\
\text { (b) Where: } \\
\text { (c) Number of times: } \\
\text { (d) AA/NA? (circle response) }\end{array}$} \\
\hline \multirow{2}{*}{\multicolumn{5}{|c|}{$\begin{array}{l}\text { 5. Did patient bring their medication or a list of medication to appt? } \square \text { No } \\
\text { 6. Is this visit related to any of the following? (check all that apply): } \\
\square \text { WSIB } \square \text { medical/legal } \square \text { accident }\end{array}$}} \\
\hline & & & & \\
\hline \multicolumn{5}{|c|}{ 7. Pain and Chemical Dependency Worksheet (Gourlay): } \\
\hline \multicolumn{5}{|c|}{ a) Worsening AM pain: $\square$ No $\square$ Yes } \\
\hline \multicolumn{5}{|c|}{ b) Max alcohol intake (__ SD 24/hr) } \\
\hline \multicolumn{5}{|c|}{ d) Nicotine: $\square$ No $\quad \square$ Yes $\quad$ PPD: $\square$} \\
\hline \multicolumn{5}{|c|}{ e) Prescription drugs: Off street? $\square$ No $\square$ Yes Borrowed? $\square$ No $\square$ Yes } \\
\hline \multicolumn{5}{|c|}{ f) Family Psychiatric Hx ( $\square$ Mother $\square$ Father $\square$ Sibs $\square$ Adopted) (Dx): } \\
\hline \multicolumn{5}{|l|}{ g) Personal Psychiatric $\mathrm{Hx} / \mathrm{Dx}$ : } \\
\hline \multicolumn{5}{|c|}{$\begin{array}{l}\text { h) Suicide: } \\
\quad \text { Past suicide attempts } \square \text { No } \square \text { Yes } \\
\quad \text { Current risk: } \square \text { No } \square \text { Yes }\end{array}$} \\
\hline \multicolumn{5}{|c|}{ i) $\square$ Hx of Trauma: (Emotional/Physical/Sexual) (circle all that apply) } \\
\hline \multicolumn{5}{|c|}{ 8. Urine screen sent: $\square$ No $\square$ Yes $\square$ Refused } \\
\hline \multicolumn{5}{|l|}{$\begin{array}{l}\text { 9. Overall risk assessment } \\
\text { (based on clinical judgement): }\end{array}$} \\
\hline$\square$ Low & Mod & & $\square$ High & \\
\hline
\end{tabular}

Appendix A) AA Alcoholics Anonymous; CAGE-AID Have you ever felt you should Cut down on your drinking? Have people Annoyed you by criticising your drinking? Have you ever felt bad or Guilty about your drinking? Have you ever had a drink first thing in the morning to steady your nerves or get rid of a hangover (Eye-opener)? Adapted to Include Drugs; Dx Diagnosis; Hx History; LSD Lysergic acid diethylamide; NA Narcotics Anonymous; PCP l-(l-phenylcyclohexyl)-piperidine); PPD Packs per day; WSIB Workplace Safety and Insurance Board

\section{REFERENCES}

1. Gourlay DL, Heit HA, Almahrezi A. Universal precautions in pain medicine: A rational approach to the treatment of chronic pain. Pain Med 2005;6:107-12.

2. Cowan DT, Allen LG, Griffiths P. A pilot study into problematic use of opioid analgesics in chronic non-cancer pain patients. Int J Nurs Studies 2002;39:59-69.

3. Cowan DT, Wilson-Barnett J, Griffiths P, Allen LG. A survey of non-cancer pain patients prescribed opioid analgesics. Pain Med 2003;4:340-51.

4. Compton P, Darakjian J, Miotto K. Screening for addiction in patients with chronic pain and "problematic" use: Evaluation of a pilot assessment tool. J Pain Symptom Manage 1998;16:355-63.

5. Kouyanou K, Pither CE, Wessley S. Medication misuse, abuse and dependence in chronic pain patients. J Psychosom Res 1997;43:497-504.

6. Manchikanti L, Manchukonda R, Pampati V, et al. Does random urine drug testing reduce illicit drug use in chronic pain patients receiving opioids? Pain Physician 2006;9:123-9.

7. Brown R L, Rounds LA. Conjoint screening questionnaires for alcohol and other drug abuse: Criterion validity in a primary care practice. Wis Med J 1995;94:135-40.

8. Webster LR, Webster RM. Predicting aberrant behaviors in opioidtreated patients: Preliminary validation of the Opioid Risk Tool. Pain Med 2005;6:432-42.

9. Passik SD, Kirsh KL, Whitcomb L, et al. A new tool to assess and document pain outcomes in chronic pain patients receiving opioid therapy. Clin Ther 2004;26:552-61.

10. Bair MJ, Robinson RL, Katon W, Kroenke K. Depression and pain comorbitity: A literature review. Arch Int Med 2003;1693:2433-45.

11. Gourlay D, Heit H. Universal precautions: Managing the inherited pain patient. Pain Med 2009;10(Suppl 2):S115-S23.

12. Passik SD. Pain and addiction interface. Pain Med 2008;9:631-3. 


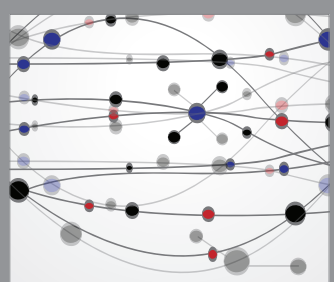

The Scientific World Journal
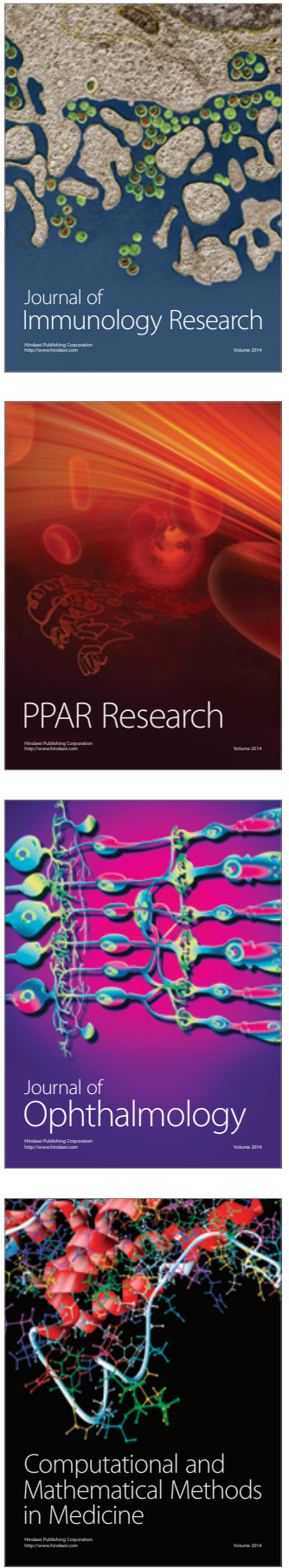

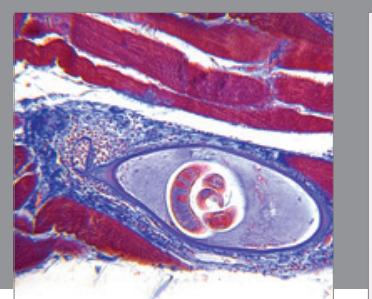

Gastroenterology Research and Practice

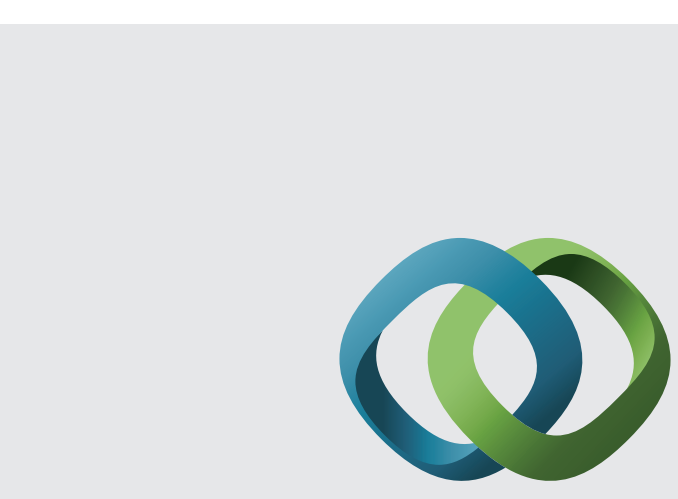

\section{Hindawi}

Submit your manuscripts at

http://www.hindawi.com
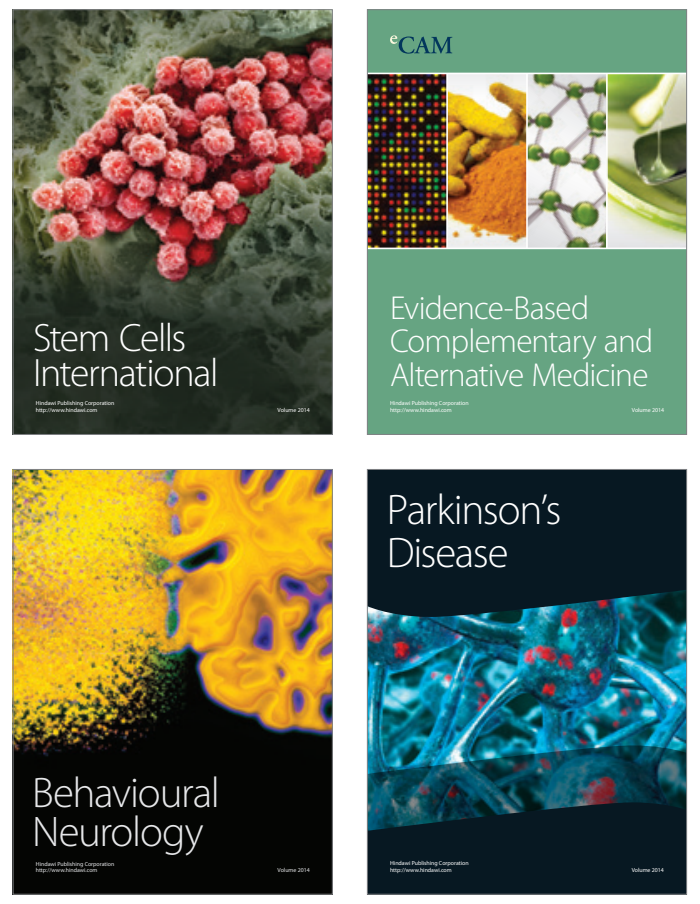
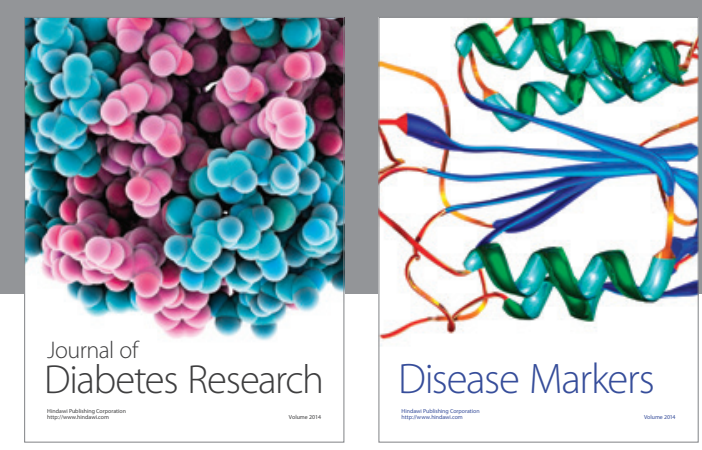

Disease Markers
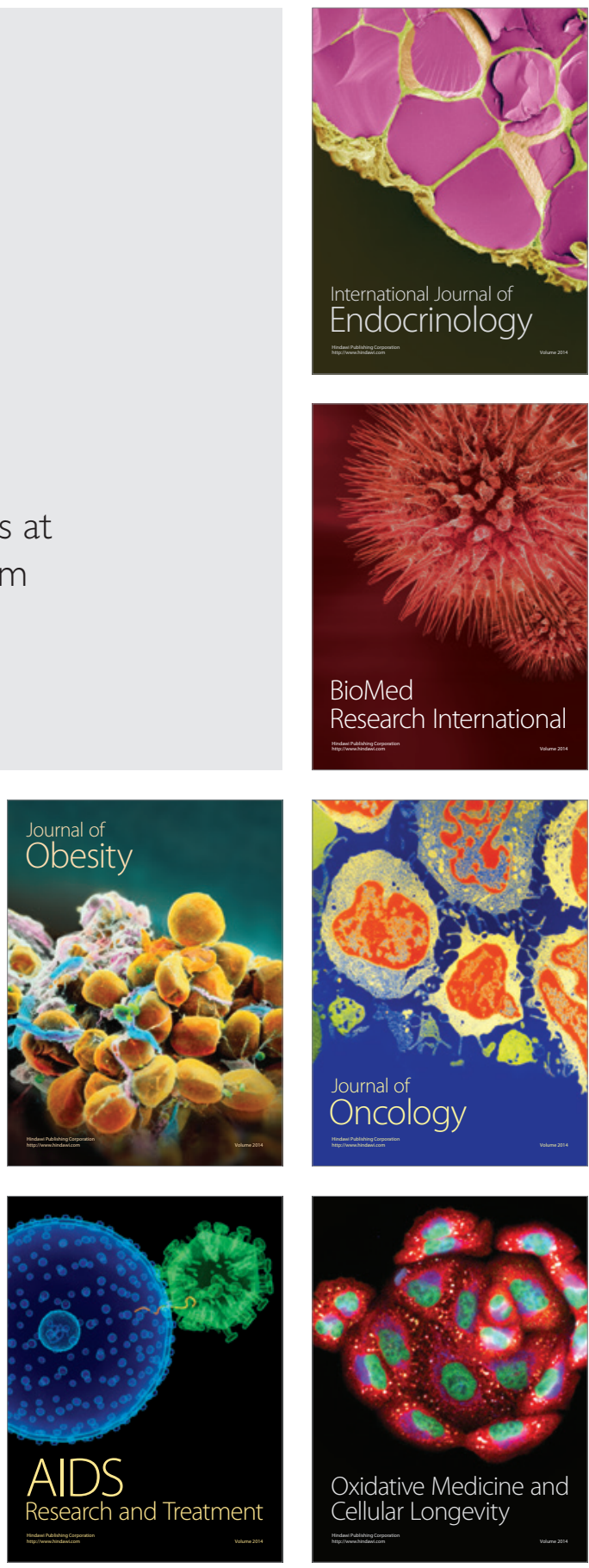